\title{
O Uso do Aplicativo Plickers: Tecnologia Móvel e Metodologia Ativa na Aula de Inglês
}

\author{
Izabel Silva Souza D’Ambrosio', Anne Alilma Silva Souza Ferrete ${ }^{2}$ \\ ${ }^{1}$ Professora Efetiva do Estado SEED / SE - Colégio Estadual Prefeito Anfilófio \\ Fernandes Viana - Umbaúba / SE - Brazil. Doutoranda Programa de Pós Graduação em \\ Educação da Universidade Federal de Sergipe (PPGED-UFS) \\ 2 Departamento de Educação - Programa de Pós Graduação em Educação (PPGED) - \\ NUCA-Núcleo de Comunicação e Arte (Vice-líder) - Universidade Federal de Sergipe \\ (UFS) - São Cristóvão - Sergipe - Brazil \\ Idambrosio66@yahoo.com.br, alilma.ferrete50@gmail.com
}

\begin{abstract}
This paper aims to deal with the subject of mobile technology, bridging the gap between theory and practice in the classroom scenario in the English class in the public education. The discussion is about proposed changes to the teaching of the 20th century (CASTELL, 1999; FREIRE, 1999) with the presence of strategies focused on the active methodology (BACICH, 2018), merging hybrid teaching and collaborative activities. The context of teaching, goes through changes that stimulate the teaching of digital technologies. The use of digital resources and the offline game Plickers are highlighted as elements of the digital technologies in this work.
\end{abstract}

Resumo. $O$ presente artigo tem por objetivo abordar a temática da tecnologia móvel realizando uma ponte entre teoria e prática no cenário de sala de aula na disciplina de inglês do ensino público. A discussão gira em torno de mudanças propostas para o ensino do séc. XXI (CASTELL,1999; FREIRE, 1999) com a presença de estratégias voltadas para a metodologia ativa (BACICH,2018), mesclando o ensino híbrido e atividades colaborativas. $O$ contexto do ensino passa por mudanças que estimulam o ensino das tecnologias digitais. A utilização da metodologia ativa e do jogo offline Plickers estão destacados como elementos das tecnologias digitais neste trabalho.

\section{Introdução}

Devemos ao nosso passado, os embriões microscópicos que se desenvolveram e nos trouxeram a contemporaneidade cerceada de vivências tecnológicas digitais, que se desenvolveram ao longo do tempo através das técnicas, invenções e inovações. Deveremos ao nosso futuro, o desenvolvimento dos embriões microscópicos do presente, que nos levarão a um futuro de prospecção tecnológica mais avançada e inimaginável, assim como a própria evolução da humanidade. A Inteligência Artificial (IA), microships inseridos nos corpos, incremento da vigilância digital, a Realidade Virtual (RV), a presença dos smartphones na comunicação e outros mais, são eventos da nossa contemporaneidade que desaparecerão ou serão transformados em outros eventos mais modernos ao longo do tempo. 
O contínuo processo evolutivo nos leva a fazer mudanças muitas vezes espontâneas, outras não. Mudanças que modificam nossas experiências e nossa sociedade, economia, política, esferas que regem o nosso cotidiano. Ferrete (2010, p.11), expõe o papel da educação na questão de transformação na sociedade ressaltando a questão de reformulação curricular e de método de ensino. Dentro deste contexto, a educação escolar se pressupõe como elemento transformador transformado, já que sofre influência e dita algumas mudanças advindas das Tecnologias Digitais de Informação e Comunicação (TDIC) em suas práticas pedagógicas, na formação de seu corpo docente e discente, no surgimento de novos modelos de pensamento e estruturas curriculares e outras. Rodeados pelas TDIC, pelas Tecnologias Móveis (TM), somos agentes e pacientes deste processo.

Castells (1999), afirma que o século XXI será marcado pela tecnologia móvel, da difusão da informação e aumento da comunicação interativa. Reafirmando o pensamento de Castells de 1999, na contemporaneidade, novas medidas vêm sendo tomadas diante da inserção das TDIC na Educação e o novo cenário que nossa sociedade apresenta, adequando assim novas regulamentações diante desta realidade.

A Base Nacional Comum Curricular $(\mathrm{BNCC})^{1}$, definida pela Lei de Diretrizes e Bases (LDB n ${ }^{\circ}$ 9.394/1996) norteia os currículos das redes de ensino das Unidades Federativas, do ensino público e privado. A BNCC designa competências, habilidades e conhecimentos que norteiam o ensino da educação brasileira. Em de acordo com a BNCC do Ensino Médio, este é subdivido em áreas do conhecimento, cujo objetivo é integrar área de conhecimento, cada área é definida por competência específica, que são descritas por habilidades. Dentro deste cenário, a BNCC se preocupa com o contexto geral de transformação da sociedade, com a preparação do jovem neste contexto, e nele se encontra o grande marco desta era: as tecnologias digitais. Em articulação com as competências gerais as dimensões tecnológicas contemplam o objetivo de aprendizagem. (BRASIL, 2018).

A BNCC na seção: As tecnologias digitais e a Computação reafirma que a,

[...] cultura digital: envolve aprendizagens voltadas a uma participação mais consciente e democrática por meio das tecnologias digitais, o que supõe a compreensão dos impactos da revolução digital e dos avanços do mundo digital na sociedade contemporânea, a construção de uma atitude crítica, ética e responsável em relação à multiplicidade de ofertas midiáticas e digitais, aos usos possíveis das diferentes tecnologias e aos conteúdos por elas veiculados, e, também, à fluência no uso da tecnologia digital para expressão de soluções e manifestações culturais de forma contextualizada e crítica. (BRASIL, 2018, p.474)

Desta forma, a construção do conhecimento vem aos poucos, diante da realidade do ensino público brasileiro se adequando para ofertar a esta geração digital a possibilidade de integrar as propostas do currículo em sua realidade prática fomentando as práticas pedagógicas aliadas as TDIC.

A geração de nativos digitais, segundo Prensky (2001), em seu artigo Digital Natives, Digital Immigrants - Nativos Digitais, Imigrantes Digitais - diz que, "nossos alunos mudaram radicalmente. Os alunos de hoje não são mais as pessoas ao qual o nosso

\footnotetext{
${ }^{1}$ http://basenacionalcomum.mec.gov.br/
} 
sistema educacional foi designado a ensinar."2 Este pensamento referido por Prensky em 2001, se repete em um processo cíclico de transformação das tecnologias digitais no processo de ensino-aprendizagem devido a rápida mudança das TDIC e TM. Atualmente, os alunos estão mais imersos e inseridos no meio digital comparando-se a 2001 devido à vasta expansão destas tecnologias, principalmente a dos dispositivos móveis conectados à internet e de sua presença na educação. Novos tempos, novas necessidades, novas descobertas e conforme corroborado por Morin (2012), novos embriões microscópicos que nos levarão a outras prospecções.

Rememorando uma educação ultrapassada, Freire (1987), dialoga em Pedagogia do Oprimido, que houve tempos atrás uma concepção de educação bancária, cuja linha de pensamento não cabe mais neste século. Por educação bancária, tínhamos o educador como detentor do conhecimento e reprodutor das ideias a serem depositadas e absorvidas nas mentes dos educandos. Estes ocupavam um papel de passividade dentro do processo de aprender. Esta proposta se alinhava ao modelo da escola tradicional do séc. XIX. Entretanto, estas ideias vão de encontro a proposta de escola do séc. XXI, que preconiza o educando como protagonista no seu processo de aprendizagem, a vivência do educando associada à sua experiência, experiência reflexiva, significativa onde a teoria e a prática estão vinculadas. Esta linha de pensamento, se identifica com o pensamento de Dewey (2010) com sua Escola $\mathrm{Nova}^{3}$, e os pensamentos de Freire (2016) que estimulam a participação, autonomia, diálogo, estímulo a curiosidade, o learn by doing - aprender fazendo - e outros. A experiência, preconizada por Dewey (2010), esclarece que,

A experiência educativa é, pois, essa experiência inteligente, em que participa o pensamento, através do qual se vêm a perceber relações e continuidades antes não percebidas. [...]. A experiência alarga, deste modo, os conhecimentos, enriquece o nosso espírito e dá, dia a dia, significação mais profunda à vida. (DEWEY, 2010, p.37).

$\mathrm{O}$ ato de aprender através da experiência, torna o indivíduo parte integrante do processo, estimulando o cognitivo e ampliando a sua percepção de mundo. O pensamento anteriormente referenciado é também reforçado por Haydt (2011), que aponta dentre alguns tópicos, os seguintes: "A Aprendizagem é um processo dinâmico que depende da atividade mental do educando e que se dá por meio da mobilização de seus esquemas de pensamento", valorizando assim a construção de conhecimento através da ativação do estímulo cognitivo que são acionados pelas práticas de sala de aula. O outro tópico, é a valorização as atividades "naturais e espontâneas dos educandos, como jogos e brincadeiras" preconizando a ideia da Escola Nova que é o de enfatizar métodos ativos e interativos. Por conseguinte, a relação de proximidade dos alunos com as tecnologias digitais, e de jogos online, se bem direcionada, é um canal de aprendizagem e reforça o princípio da metodologia ativa desenvolvido pela Escola Nova.

A participação das TDIC na educação, muda a relação do educador e educando no processo da aprendizagem intelectual, torna-se mais ampla se bem utilizada. Modelos de uma sala de aula híbrida ${ }^{4}$ vêm ditando novas concepções, metodologias, linguagens

\footnotetext{
${ }^{2}$ Our students have changed radically. Today's students are no longer the people our educational system was designed to teach. (Tradução própria, do original)

${ }^{3}$ A escola Nova empreendeu uma crítica a escola tradicional (LOURENÇO FILHO, 1963)

${ }^{4}$ Por híbrido, entende-se misturado, mesclado, blended learning
} 
online e off-line, mudanças de postura do alunado e professorado, assim como alterando as práticas pedagógicas.

Baseada nas reflexões mencionadas anteriormente, e em outras posteriores, farei através deste artigo uma correlação entre a teoria e prática envolvendo o ensino híbrido consolidado através de ações que envolvem a metodologia ativa ${ }^{5}$ associada as TM, a abordagem comunicativa e colaborativa no ensino de inglês, disciplina em foco.

\section{Metodologia aplicada: da teoria à prática}

A importância da Língua Estrangeira (LE), na vida pessoal e profissional das pessoas ganha destaque para a Língua Inglesa (LI), que é uma língua de uso global e que amplia o contato multicultural e multilinguístico dos indivíduos (PCN, 2000; OCEM, 2006).

A prática foi fundamentada em aulas da disciplina de inglês, na rede pública do ensino médio e superior. O objetivo da aula foi o de fomentar a habilidade de leitura de forma que os alunos ao final desta fossem capazes de utilizar estratégias de leitura para a compreensão do texto. Para levantamento e análise das informações aplicamos um questionário dos alunos que passaram pela experiência. As atividades aplicadas trabalharam com a interação, a aprendizagem compartilhada, a tecnologia móvel com o aplicativo Plickers, o dinamismo e consolidação de conteúdo.

A metodologia aplicada foi baseada no estudo de caso baseada em Lüdke e André (1986, p.17), que trata de um estudo baseado em sua singularidade, no valor particular que incide nele mesmo que no decorrer da pesquisa venha a apresentar semelhanças com outros casos. Nessa mesma linha de raciocínio quanto a particularidade Merriam (1988) que traz pontos de definição em André (2005, p.17) ressalta que atribui quatro características para o estudo de caso qualitativo: particularidade, descrição, heurística e indução.

O resultado deste questionário, aplicado pelo google docs, que obteve a resposta de 65 alunos, contempla reflexões que estão presentes na elaboração deste trabalho em conjunto com algumas fases da aula que serão relacionadas, fazendo uma ponte entre teoria e prática. Questões como: com que frequência faz uso das redes sociais? Faz uso das tecnologias digitais para estudar, ampliar seu conhecimento? Acha positivo o uso de jogos (online ou off-line) na sala de aula para ajudar na aprendizagem? Referente ao potencial educativo do plickers você considera que: promove o aprendizado; estimula a participação na aula, promove autonomia, promove colaboração entre os alunos, promove uma maior interação entre professor e alunos, promove a revisão de conteúdos e outros, o que acha da aula de inglês? Você sentiu dificuldades em usar o Plickers? Se sim, de que forma? Você prefere aulas com atividades: individuais, em dupla ou em grupo?

A descrição da prática teve por início na atividade inicial que foi a de atrair a atenção dos alunos, gerar curiosidade e introduzir os tópicos a serem trabalhados em aula através de um slide de PPT (Power Point) que apresentou em sua execução alguns recursos tecnológicos digitais: o Bloggif ${ }^{6}$, o Bitmoji $^{7}$ e a gravação de áudio ${ }^{8}$. O Bloggif, é uma ferramenta online que possibilita a criação de um gif com variados efeitos através de textos, imagens, vídeos, colagem etc. A junção de recurso audiovisual não somente

\footnotetext{
${ }^{5}$ Metodologia ativa "são estratégias de ensino centradas na participação efetiva dos estudantes na construção do processo de aprendizagem, de forma flexível, interligada e híbrida" (BACICH, 2018, p.4)

${ }^{6}$ https://pt.bloggif.com/

${ }^{7} \mathrm{https} / / /$ www.bitmoji.com/

${ }^{8} \mathrm{https}: / /$ online-voice-recorder.com/pt/
} 
atraiu a atenção como foi personalizada para o objetivo da aula, o recurso audiovisual geralmente "se dirijam inicialmente aos órgãos sensoriais, eles chegam também a acionar e mobilizar os esquemas mentais mais elevados" (HAYDT, 2011). Neste caso a imagem utilizada foi o rosto da professora, pois o objetivo foi o de mostrar a imagem falando com os alunos agregando a esta o recurso de gravação de áudio. Esta junção (imagem e áudio) uniu dois veículos digitais (bloggif e bitmoji) tornando a apresentação mais lúdica e interessante, atraindo a atenção dos alunos e conforme exposto por Haydt (2011), acionando seus órgão sensoriais.

Incitar o discente a pensar é um dos papéis do professor, aguçar a sua imaginação, a curiosidade, ampliar sua percepção, a formação de uma nova opinião, de um pensamento crítico ao se deparar com modelos, realidades diferentes. Entretanto, esta experiência precisa de uma dinâmica e continuidade para a aula. A sequência da aula tem por objetivo primar a significação dos conteúdos apresentados em um contexto.

O estágio seguinte foi o ensino de vocabulário como atividade de pré-leitura que é um estágio importante para que o alunos se apropriem do léxico na execução da leitura, não somente na forma escrita, mas também na prática da pronúncia e contextualização. O vocabulário fará sentido para ele e será um elemento na hora da construção de compreensão do texto. Não somente o aprendizado do léxico, mas também o conteúdo do texto deve ser significativo para o discente, de forma que o conteúdo seja trazido para a sua realidade. A correlação entre o conteúdo e a realidade do aluno deve ser estabelecida para fazer sentido para ele. A Teoria Significativa de Ausubel, afirma que este conhecimento prévio deve ser valorizado para que o raciocínio construa associações e se transformam em estruturas mentais (PELLIZARI, 2002).

Dando continuidade, uma outra fase foi a exploração do título para trazer à luz o conhecimento prévio do aluno. Este conhecimento é valorizado, pois os alunos se expõem trazendo exemplos de sua realidade e, assim, se envolvem ampliando sua aprendizagem.

O texto foi dividido em partes, e cada parte foi trabalhada por um grupo de alunos. Em seguida, no sentido rotacional, um representante de cada grupo passava para a equipe seguinte as informações que eram compartilhadas até todos percorrerem todos os grupos. Ao final, a estória foi relatada por todos dando-se a construção de compreensão do texto. $\mathrm{O}$ texto foi segmentado para que sua compreensão fosse trabalhada em partes e, construído o todo ao final no compartilhamento dos alunos com uma breve discussão. Esta discussão reforça o aprender com o outro, ouvir o outro e se articular. Prensky (2007, p. 2$)^{9}$, ressalta que esta estratégia é positiva, pois os alunos querem

[...] trabalhar em grupos. Fazer projetos. Ter a oportunidade de compartilhar as suas ideias com seus pares e ouvir o que seus colegas têm a dizer. Ser desafiado. Ser questionado por perguntas interessantes. Ser ouvido. Ser respeitado (tradução própria).

O trabalho em grupo proporciona o trabalho colaborativo, e de acordo com os dados da figura 1 abaixo: 26,2\% dos alunos preferem trabalhar em dupla, 61,5\% trabalhar em grupo e $12,3 \%$ com atividades individuais.

\footnotetext{
${ }^{9}$ Working in groups. Doing projects. Having the opportunity to share their ideas with their peers and hear what their peers have to say. Being challenged. Being asked interesting questions. Being listened to. Being respected (Texto original, tradução própria).
} 
VIII Congresso Brasileiro de Informática na Educação (CBIE 2019)

Anais dos Workshops do VIII Congresso Brasileiro de Informática na Educação (WCBIE 2019)

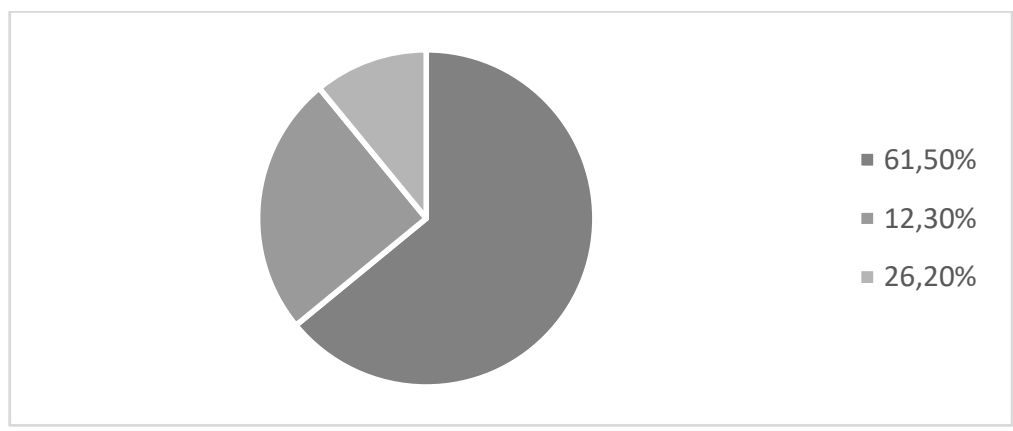

Figura 1. Trabalho em grupo $61,5 \%$, dupla $26,2 \%$ ou individual $12,3 \%$

Estes dados reforçam a importância do trabalho em parceria, e que o alunado se identifica com esta prática. A Luz do pensamento de Vygotsky (2008), o teórico atribui à questão de construção de conhecimento do indivíduo através do compartilhamento. $\mathrm{O}$ conhecimento é adquirido através da troca com o parceiro, com o outro. A bagagem pessoal do indivíduo aumenta a partir das trocas sociais. Nesse pressuposto, o homem é construído através da sua relação com o outro, o que também se dá diante das práticas de ensino que evidenciam o contato com um outro sujeito. As atividades em pares e em grupos possuem esta característica.

Quanto a aprendizagem ativa e significativa,

A aprendizagem é ativa e significativa quando avançamos em espiral, de níveis mais complexos de conhecimento e competência em todas as dimensões da vida. Esses avanços realizam-se por diversas trilhas com movimentos, tempos e desenhos diferentes, que se integram como mosaicos dinâmicos, com diversas ênfases [...]. (BACICH, 2018, p.2)

A integração entre as atividades e a sequência lógica em consonância com o dinamismo, implica em um ensino de práticas que contempla a construção das etapas para se atingir os objetivos e sub-objetivos. Tecer as fases de aula, cada qual atendendo a sua perspectiva dentro do quadro geral para atingir ao objetivo final.

Trazendo como proposta de uma aula mesclada e com o uso da TM com atividade que gerasse dinamismo e aprendizagem significativa, o Plickers, ${ }^{10}$ uma ferramenta da web, foi em seguida aplicada em sala de aula.

A presença de jogos e de tecnologia digital como prática pedagógica enriquece o processo de ensino-aprendizagem. De acordo com alguns relatos dos participantes, na tabela 1 abaixo, a presença de jogos e de uso das tecnologias digitais proporcionam: promove a aprendizagem além de estimular a participação dos alunos na aula, promove interação entre os alunos, facilita a compreensão do conteúdo, o aprendizado é realizado de forma divertida, atrai a atenção de alunos entre outros. Os relatos ratificam a posição anteriormente referenciada por Bacich (2018).

10 É uma ferramenta disponível na versão web e aplicativo para dispositivos móveis, de administração de testes rápidos, que permite o professor escanear as respostas e conhecer em tempo real o nível da turma quanto ao entendimento de conceitos e pontos chaves de uma aula. $\mathrm{O}$ app gera e salva automaticamente o desempenho individual dos alunos, criando gráficos e dados. Fonte: http://aulaincrivel.com/plickers/ 
VIII Congresso Brasileiro de Informática na Educação (CBIE 2019)

Anais dos Workshops do VIII Congresso Brasileiro de Informática na Educação (WCBIE 2019)

Porque é uma forma legal e descontraída de aprender.

Acredito que quanto maior o número de ferramentas de aprendizagem, maiores serão as possibilidades do aprendizado

Pois a tecnologia oferece uma gama maior e mais interativa de conteúdos, como também, deixa o aprendizado mais dinâmico

Por meio deste recurso, tanto profissionais quanto alunos, podem desenvolver atividades que facilitem a execução de um trabalho, bem como obter melhores resultados de maneira interativa e lúdica, de maneira atrativa e agregada ao crescimento acadêmico

É uma forma interessante e divertida de se aprender

È positivo porque, dá mais prazer em realizar as atividades de sala de aula, além de ser uma ferramenta bem interativa

Torna a aula mais divertida e dinâmica, além de revisar o conteúdo, por conta disso pode auxiliar no processo de memorização das atividades

Acho que ajuda bastante na fixação do conteúdo

Pois haverá mais interesse da parte dos alunos e uma interação maior em relação ao professor e aluno, além de entretenimento

Aumentar aprendizado e dinâmica

Temos que alinhas nossas práticas educacionais com o contexto informacional que vivemos. Os jogos estimulam as possibilidades e promovem momentos lúdicos de aprendizagem

Se torna uma forma mais divertida e diferente de aprendizagem

Tabela 1. Uso de jogos online / offline em sala de aula

A idade dos participantes foi de $23,1 \%$ entre 15 e 17 anos e $76,9 \%$ de 18 anos ou mais, sendo a maior idade de 26 anos. As práticas de ensino foram realizadas com alunos do ensino médio e superior, por isso a variação de idade apresentada.

Um público cuja geração (re)significa seu modus operandi ${ }^{11}$ nas redes sociais, principalmente, no tocante à sua maneira de socialização online e à exposição de sua exposição nas redes. 98,5\% dos jovens que responderam ao questionário estão presentes nas redes sociais e acessam Instagram, Facebook, Twitter, Telegram. Do grupo participante, em um universo de 100\%, 76,9\% está presente nas redes sociais de 30 a $70 \%$ do seu tempo. Os dados demonstram a relação de proximidade do público jovem com as redes sociais. A presença do ciberespaço na vida dos jovens de hoje mudou a forma das relações, as conexões se tornaram espaciais; a movimentação social é mais fluida, e o virtual tem um papel transformador e acelerador na dinâmica de vida atual.

Diante do exposto, Lévy (1999), nos brinda com as seguintes palavras sobre o ciberespaço:

Mesmo quando não é acompanhada de encontros, a interação no ciberespaço continua sendo uma forma de comunicação. Mas, ouvimos

\footnotetext{
${ }^{11}$ Modus operandi - modo de operação
} 
VIII Congresso Brasileiro de Informática na Educação (CBIE 2019)

Anais dos Workshops do VIII Congresso Brasileiro de Informática na Educação (WCBIE 2019)

algumas vezes dizer, algumas pessoas permanecem horas "diante de suas telas", isolando-se assim dos outros. Os excessos certamente não devem ser encorajados. Mas dizemos que alguém que lê "permanece horas diante do papel"? Não. Porque a pessoa que lê não está se relacionando com uma folha de celulose, ela está em contato com um discurso, uma voz, um universo de significados que ela contribui para construir, para habitar com sua leitura. $\mathrm{O}$ fato de o texto ser apresentado na tela não muda nada. Trata-se igualmente de leitura [...]. (LÉVY, 1999, p.163).

A relação das pessoas com as redes sociais é uma forma diferente de comunicação, de relação, não excluindo as relações presenciais. Os nativos digitais são detentores de um potencial de comunicação, integração no mundo online muito maior que os migrantes digitais. Este potencial, sendo bem aplicado, assume um papel importante na vida pessoal, estudantil e profissional da pessoa. O volume de informação circulante na internet é infinito e de fácil acesso possibilitando ao público pesquisar, ter acesso a conteúdos que antes da internet eram mais restritos.

Desta forma, a metodologia ativa foi aplicada nesta aula de inglês com a consolidação de conteúdo através de práticas dinâmicas e que geraram uma inter-relação entre os participantes.

\section{O Jogo Plickers}

Para a aplicação do Plickers é necessário acesso à internet por parte do docente, baixar o aplicativo, ter um dispositivo móvel, um computador, um data show e cartões específicos que possuem um QR Code fornecidos pelo site do jogo.

Para a aplicação do jogo através do site do Plickers, o professor prepara questões relacionadas ao seu conteúdo que são acessadas através do app no celular e exibidas no data show para os alunos. Os alunos devem posicionar a letra correspondente a resposta para o lado de cima do cartão (cada lado do cartão possui uma letra A, B, C, D). Os alunos podem discutir rapidamente as questões. Cada questão possui um tempo de resposta. Em tempo real as respostas serão exibidas na projeção do data show devido a leitura dos cartões com QR Code pelo celular do professor. Os resultados são exibidos na projeção pela identificação do número do cartão e a letra da resposta.

Observou-se a atração e interesse por parte dos envolvidos: alteração na postura do corpo para frente como reflexo físico devido a interação com o jogo, uma maior reflexão para responder, maior concentração e um movimento voluntário dos alunos que se encontravam na parte de trás da sala e se moveram para a parte da frente. Houve uma movimentação atípica por parte dos alunos ao se engajarem nas atividades, principalmente no jogo que demonstrou maior interesse e conexão.

Analisando as informações coletadas como forma de avaliação e aporte para a compreensão dos fatos narrados, percebe-se que o potencial educativo do jogo Plickers e das atividades mencionadas foram positivas.

\section{Considerações Finais}

Em se tratando de uma aula de inglês, onde parte dos alunos $(74,6 \%)$ disseram gostar da aula e $25,4 \%$ acharam a aula regular, a inclusão de atividades que insiram as TDIC, além de atividades em grupos, tornam a aula mais ativa e significativa. Esta inserção aumenta 
VIII Congresso Brasileiro de Informática na Educação (CBIE 2019)

Anais dos Workshops do VIII Congresso Brasileiro de Informática na Educação (WCBIE 2019)

a tendência de melhora na aprendizagem dos alunos. Cabe ao docente, como mediador do conhecimento, propor em suas aulas, recursos, estratégias e metodologias que desenvolvam o potencial do alunado diante das diversas possibilidades de aquisição do conhecimento.

O desenvolvimento da competência linguística do inglês foi trabalhada com as atividades mencionadas acima e atingiram seu objetivo de aula. Isso demandou planejamento, pesquisa, conhecimento e inovação, com a proposta de oferecer uma aula que envolvesse os alunos no processo de aprender. Entretanto, cabe ressaltar que a formação docente, recursos institucionais, aplicabilidade de regulamentações, projetos e uma variedade de outros fatores, são pontos nevrálgicos dentro do contexto da educação pública brasileira. Mesmo com mudanças curriculares, inúmeras pesquisas e teorias, a educação precisa não somente da valorização governamental, mas da responsabilidade de um país que tenha por base uma educação séria que contemple as classes mais baixas da sociedade.

\section{References}

Bacich, L e Moran, J. (2018) "Metodologias ativas para uma educação inovadora: uma abordagem teórico-prática”, Organizadores, Lilian Bacich, José Moran. Porto Alegre: Penso Editora.

Brasil. Secretaria de Educação Fundamental. "Parâmetros curriculares nacionais: terceiro e quarto ciclos do ensino fundamental: língua estrangeira" Secretaria de Educação Fundamental. Brasília: MEC/SEF, 2000.

Brasília. Ministério da Educação, Secretaria de Educação Básica. "Orientações curriculares para o ensino médio" volume 1, 2006.

Castells, M. (1999) "A Era da Informação, economia e cultura: a sociedade em rede." V.1, São Paulo: Paz e Terra.

França, L. C. Monteiro; Ferrete, A. A. S; GOUY e Borba, G. (2010) "Educação a distância: ambientes virtuais, TIC e universidades abertas”. Aracaju: Criação, p. 30.

Freire, P. (2016). "Pedagogia da autonomia." 53a ed. Rio de Janeiro: Paz e Terra. . (1987). “A Pedagogia do Oprimido.” $17^{\mathrm{a}}$ ed. Rio de Janeiro: Paz e Terra.

Haydt, R. C. C. (2011) “Curso de didática geral.” $1^{\text {a }}$ Edição-São Paulo: Ática.

Lévy, P.(1999) “Cibercultura.” Editora 34.

Lourenço Filho, M.B. (1963) "Introdução ao Estudo da Escola Nova."

Morin, E. (2012) "Para onde vai o mundo?" tradução de Francisco Morás. 3 ed. Petrópolis, RJ: Vozes.

Palfrey, J. e Gasser, U. (2011) "Nascidos na era digital: entendendo a primeira geração de nativos digitais." Penso Editora.

Pelizzari, A. et al. (2011) "Teoria da aprendizagem significativa segundo Ausubel." revista PEC, v. 2, n. 1, p. 37-42. 
VIII Congresso Brasileiro de Informática na Educação (CBIE 2019)

Anais dos Workshops do VIII Congresso Brasileiro de Informática na Educação (WCBIE 2019)

Prensky, M. (2001) “Digital Natives, Digital Immigrants.” Part 1. On the horizon, v. 9, n. 5, p. 1-6.

Vygotsky, L. S.(2008) “Pensamento e linguagem.” 4. ed. São Paulo: Martins Fontes.

Westbrook, R. e Teixeira, A. (2010) “John Dewey.” José Eustáquio Romão e Verone Lane Rodrigues (Org.). Coleção educadores MEC. Recife: Fundação Joaquim Nabuco, Ed. Massangana. 